\title{
EDITORIAL
}

\section{Diagnosing pulmonary hypertension: is there a revival of the electrocardiogram?}

\author{
R. Speich
}

ven in the most recent and largest series of patients with pulmonary arterial hypertension $(\mathrm{PAH})$, the time interval between the onset of symptoms and eventual diagnosis was a mean of 27 months [1]. This represents an absolutely unacceptable delay, which is tragically even longer than the mean of $2 \mathrm{yrs}$ in the first series of the US National Institutes of Health (NIH) registry about 20 yrs ago [2]. Nowadays, three-quarters of patients are in World Health Organization (WHO) functional classes III or IV, have a 6-min walk distance of $\sim 330 \mathrm{~m}$ and a pulmonary vascular resistance of almost $1,000 \mathrm{dyn} \cdot \mathrm{s} \cdot \mathrm{cm}^{-5}$ at the time of diagnosis [1]. The mean pulmonary artery pressure $\left(\bar{P}_{\text {pa }}\right)$ of patients included in large randomised studies remains at values $>50 \mathrm{mmHg}$, with $60 \mathrm{mmHg}$ in the epoprostenol trial in 1996 [3] and $52 \mathrm{mmHg}$ in the Endothelin Antagonist Trial in Mildly Symptomatic Pulmonary Arterial Hypertension Patients (EARLY) study in 2008 [4]. Remarkably, the latter intended to include only patients in WHO class II, which implies that even patients with a clinically early form of the disease in fact suffer from an advanced stage of $\mathrm{PAH}$, comparable to those in WHO functional class III-IV. Hence, despite advances in therapeutic options, there is no faint hope of improvement in diagnosing PAH during the past decades. Not unexpectedly, the overall 3 -yr survival is still only $\sim 60 \%[5,6]$, a modest $20 \%$ better than our ancestors' empirical observations.

Our poor diagnostic performance with respect to the two forms of pre-capillary pulmonary hypertension (PH), i.e. PAH and chronic thromboembolic $\mathrm{PH}$, is even more surprising if one considers the obviousness of the clinical presentation. Although PH symptoms are nonspecific, there are hardly any differential diagnoses for the classical triad of 1) dyspnoea or fatigue on exertion, 2) normal lung parenchyma on chest radiography and 3) normal spirometry results. While anaemia and hyperthyroidism can easily be detected by the general practitioner, subclinical left heart disorders will most probably be diagnosed by right heart catheterisation (RHC), and in the presence of the above mentioned triad in patients with arterial hypertension, obesity and depression, a thorough work-up for $\mathrm{PH}$ is mandatory anyway.

Hence, our diagnostic incompetence is almost unforgivable. One has to state that there is not only a diagnostic triad but also

Pulmonary Hypertension Program, University Hospital, Zurich, Switzerland.

CORRESPONDENCE: R. Speich, University Hospital, Raemistrasse 100, CH-8091 Zurich, Switzerland. E-mail: rudolf.speich@usz.ch a "fatal triad" regarding the early detection of precapillary $\mathrm{PH}$, namely 1) the low specificity of symptoms, 2) the inconspicuous clinical signs and 3) the lack of the physician's awareness. Moreover, the discrepancy between the patients' apparent good health when at rest and the striking discomfort evoked by even mild exertion adds to the fatal triad. Consequently, on the one hand, $\mathrm{PH}$ patients are "discriminated against" by the paucity of symptoms in early stage of the disease and, on the other hand, when their physical limitations become apparent, they are also discriminated against from a functional and social point of view.

In this context, the study by BONDERMAN et al. [7], in the current issue of the European Respiratory Journal, is to be complimented for the authors' tremendous efforts to develop a standard noninvasive diagnostic procedure to correctly identify or exclude pre-capillary PH. They derived a diagnostic classification and regression tree (CART) from a multitude of noninvasive clinical variables. By using their algorithm, that first rules in patients with evidence of right ventricular strain (RVS) on ECG and, secondly, ruling out those with an N-terminal prohormone of brain natriuretic peptide level $\leqslant 80 \mathrm{pg} \cdot \mathrm{mL}^{-1}$, they were able to increase the diagnostic specificity of echocardiography with respect to pre-capillary $\mathrm{PH}$ by $19.3 \%$ and, hence, potentially obviate the need for RHC in $9 \%$ of patients. However, aside from the fact that the number of "unnecessary" RHCs is very low and avoiding these few investigations may be helpful only in a very high-volume centre, it has to be emphasised that RHC still remains the crucial diagnostic tool in the evaluation of patients with suspected pre-capillary, as well as post-capillary, $\mathrm{PH}$.

Notwithstanding, the current extensive analysis of a multitude of clinical features in a large cohort of patients with $\mathrm{PH}$ has, in my opinion, resulted in a very interesting and important clinical observation: namely, the fact that the ECG finding of a RVS might be a noninvasive clinical tool with a high diagnostic accuracy with respect to pre-capillary PH. So far, the ECG has been discriminated against in its role for the diagnosis of $\mathrm{PH}$. In this context, most authoritative reviews cite the figures published by AHEARN et al. [8], who described a sensitivity and specificity of just $55 \%$ and $70 \%$, respectively. However, AHEARN et al. [8] refer to the presence of right ventricular hypertrophy (RVH) defined by the criteria originally defined by SOKOLOW and LYON [9], which mainly rely on a dominant $\mathrm{R}$-wave of definite voltage in V1. However, it is well known that these criteria may grossly underestimate the frequency of RVH. Padmavati and Raizada [10], for example, found a 
sensitivity of only $19 \%$ using the criteria of SOKOLOW and LYON [9], but a value of $60 \%$ if they applied the more liberal definition of PHILLIPS and BURCH [11], who included additional associated features.

Interestingly, in the very first consecutive series of idiopathic PAH (IPAH) patients, FUSTER et al. [12] already observed ECG abnormalities, including $\mathrm{RVH}$, right axis deviation or P-pulmonale, in $95 \%$ of their patients. In the NIH cohort, the ECG signs of RVH were present in $87 \%$ of patients [2]. Admittedly, if compared to the more recent series, these two studies included somewhat more serious cases, as reflected by a $\bar{P}_{\text {pa }}$ of 64 and $60 \mathrm{mmHg}$, respectively. However, there are also later series that found a very high overall sensitivity of the ECG with respect to $\mathrm{PH}$. In the study of Bossone et al. [13], only six $(9 \%)$ out of 64 consecutive patients had a normal ECG if interpreted by a cardiologist who was aware of the patients' basic clinic data. This is in contrast to a computer program and a blinded cardiologist, resulting in sensitvities of only $\sim 50 \%$, but most commonly because of a misdiagnosis of an "anterolateral ischaemia". Hence, returning to the study of BONDERMAN et al. [7], we should emphasise their reasonably high sensitivity of $77 \%$ suspecting pre-capillary PH by ECG. The crucial point of the matter is that the authors used the "RVS pattern", and not only $\mathrm{RVH}$, as their parameter to rule in patients into the precapillary $\mathrm{PH}$ group.

To date, most of us have taught their fellows and students the importance of the stringent ECG criteria for RVH in a suspected $\mathrm{PH}$ patient. Simultaneously, however, most of us had the feeling (or even the knowledge) that there is more hidden wisdom within the ECGs of our PH patients. It is neither a clearcut RVH, nor a clear-cut right bundle branch block, but rather some kind of nonspecific anterolateral conduction disturbances with corresponding repolarisation abnormalities. With their findings of RVS being the best discriminatory parameter for the selection of patients with precapillary $\mathrm{PH}$, in my opinion, BONDERMAN et al. [7] have inadvertently boosted the value of the ECG as an important clinical tool for improving the pre-test probability of pre-capillary $\mathrm{PH}$ before RHC. Their findings are consistent with a comprehensive ECG study on 86 patients with IPAH in whom the prevalence of RVS was 95\% [14]. Nevertheless, as stated in the most recent international guidelines [15], at present, the ECG cannot be recommended as a screening tool for $\mathrm{PH}$ until further studies are available.

But what about specificity? With regard to the normal population, anteroseptal repolarisation abnormalities are uncommon. In the largest series, including more than 120,000 ECGs of healthy subjects, only $4.7 \%$ showed any abnormality and as few as $0.2 \%$ exhibited features of RVS [16]. Of course, the main differential diagnosis of RVS is coronary artery disease. However, as underscored by Bossone et al. [13], these cases can be sorted out easily using their clinical presentation and the ECG itself. In coronary heart disease, the "strain" pattern is often located at the lateral or inferior leads and, if present in V1-V3, almost always accompanied by a $\mathrm{Q}$ wave [17-19]. In addition, there is only very rarely a right axis deviation [20].

In conclusion, though its main finding of a slightly increased specificity by the CART algorithm seems to be of generally limited benefit for the managment of patients with suspected $\mathrm{PH}$, the nicely conducted and laborious study of BONDERMAN et al. [7] has shown that, if interpreted on the basis of data available from the literature, the RVS pattern may add substantially to the suspicion of pre-capillary $\mathrm{PH}$ in patients with otherwise unexplained fatigue and dyspnoea on exertion. Thus, their study might lead to a revival of an old and discredited tool: the ECG. One just needs to know which parameter to look for.

\section{STATEMENT OF INTEREST}

None declared.

\section{ACKNOWLEDGEMENTS}

The author is grateful to H. Olschewski (Division of Pulmonology, Medical University of Graz, Graz, Austria) for his insightful and critical comments regarding the manuscript.

\section{REFERENCES}

1 Humbert M, Sitbon O, Chaouat A, et al. Pulmonary arterial hypertension in France: results from a national registry. Am J Respir Crit Care Med 2006; 173: 1023-1030.

2 Rich S, Dantzker DR, Ayres SM, et al. Primary pulmonary hypertension. A national prospective study. Ann Intern Med 1987; 107: 216-223.

3 Barst RJ, Rubin LJ, Long WA, et al. A comparison of continuous intravenous epoprostenol (prostacyclin) with conventional therapy for primary pulmonary hypertension. The Primary Pulmonary Hypertension Study Group. N Engl J Med 1996; 334: 296-302.

4 Galie N, Rubin L, Hoeper M, et al. Treatment of patients with mildly symptomatic pulmonary arterial hypertension with bosentan (EARLY study): a double-blind, randomised controlled trial. Lancet 2008; 371: 2093-2100.

5 Humbert M, Sitbon O, Chaouat A, et al. Survival in patients with idiopathic, familial, and anorexigen-associated pulmonary arterial hypertension in the modern management era. Circulation 2010; 122: 156-163.

6 Humbert M, Sitbon O, Yaici A, et al. Survival in incident and prevalent cohorts of patients with pulmonary arterial hypertension. Eur Respir J 2010; 36: 549-555.

7 Bonderman D, Wexberg P, Martischnig AM, et al. A noninvasive algorithm to exclude pre-capillary pulmonary hypertension. Eur Respir J 2011; 37: 1096-1103.

8 Ahearn GS, Tapson VF, Rebeiz A, et al. Electrocardiography to define clinical status in primary pulmonary hypertension and pulmonary arterial hypertension secondary to collagen vascular disease. Chest 2002; 122: 524-527.

9 Sokolow M, Lyon TP. The ventricular complex in right ventricular hypertrophy as obtained by unipolar precordial and limb leads. Am Heart J 1949; 38: 273-294.

10 Padmavati S, Raizada V. Electrocardiogram in chronic cor pulmonale. Br Heart J 1972; 34: 658-667.

11 Phillips JH, Burch GE. Problems in the diagnosis of cor pulmonale. Am Heart J 1963; 66: 818-832.

12 Fuster V, Steele PM, Edwards WD, et al. Primary pulmonary hpyertension: natural history and the importance of thrombosis. Circulation 1984; 70: 580-587.

13 Bossone E, Butera G, Bodini BD, et al. The interpretation of the electrocardiogram in patients with pulmonary hypertension: the need for clinical correlation. Ital Heart J 2003; 4: 850-854.

14 Kanemoto N. Electrocardiogram in primary pulmonary hypertension. Eur J Cardiol 1981; 12: 181-193. 
15 Galie N, Hoeper MM, Humbert M, et al. Guidelines for the diagnosis and treatment of pulmonary hypertension. Eur Respir J 2009; 34: 1219-1263.

16 Hiss RG, Lamb LE. Electrocardiographic findings in 122,043 individuals. Circulation 1962; 25: 947-961.

17 Linhart JW, Turnoff HB. Maximum treadmill exercise test in patients with abnormal control electrocardiograms. Circulation 1974; 49: 667-672.

18 Weiner DA, Ryan TJ, McCabe $\mathrm{CH}$, et al. Exercise stress testing. Correlations among history of angina, ST-segment response and prevalence of coronary-artery disease in the Coronary Artery Surgery Study (CASS). N Engl J Med 1979; 301: 230-235.

19 Cohn PF, Vokonas PS, Herman MV, et al. Postexercise electrocardiogram in patients with abnormal resting electrocardiograms. Circulation 1971; 43: 648-654.

20 Prajapat L, Ariyarajah V, Spodick DH. Utility of the frontal plane QRS axis in identifying non-ST-elevation myocardial infarction in patients with poor R-wave progression. Am J Cardiol 2009; 104: 190-193. 